\title{
Correction to: Verification and Design Methods for the BrainScaleS Neuromorphic Hardware System
}

\section{Andreas Grübl $^{1}$ (D) $\cdot$ Sebastian Billaudelle ${ }^{1} \cdot$ Benjamin Cramer $^{1} \cdot$ Vitali Karasenko $^{1} \cdot$ Johannes Schemmel $^{1}$}

Published online: 13 August 2020

(C) Springer Science+Business Media, LLC, part of Springer Nature 2020

\section{Correction to: J Sign Process Syst} https://doi.org/10.1007/s11265-020-01558-7

The article was published online with unupdated Fig. 4. The original article has been corrected.

a

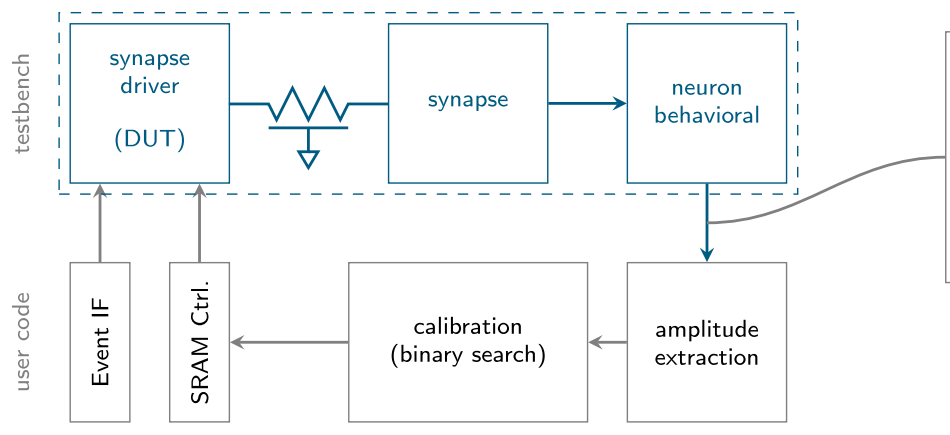

b

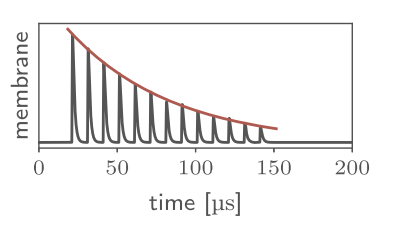

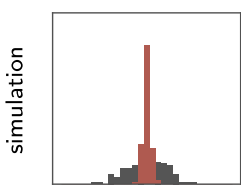

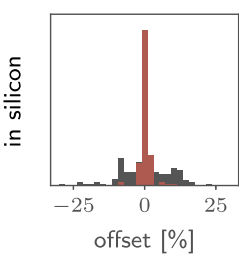

Publisher's Note Springer Nature remains neutral with regard to jurisdictional claims in published maps and institutional affiliations.

The online version of the original article can be found at https://doi.org/ 10.1007/s11265-020-01558-7

Andreas Grübl

agruebl@ kip.uni-heidelberg.de

$\triangle$ Sebastian Billaudelle

sebastian.billaudelle@kip.uni-heidelberg.de

1 Kirchhoff-Institute for Physics, Heidelberg University, INF 227,

69120 Heidelberg, Germany 